\title{
Analysis of the curriculum of medical humanities and social medicine in Colleges of Korean Medicine based on KAS2021
}

\author{
So-Youn Park ${ }^{1}$, Gwanwook Bang ${ }^{1}$, Seong-Hun $\mathrm{Choi}^{2}$, Su Jin Chae ${ }^{3 *}$ \\ ${ }^{1}$ Department of Medical Education and Humanities, School of Medicine, Kyung Hee University \\ ${ }^{2}$ Department of Anatomy and Histology, College of Oriental Medicine, Daegu Haany University \\ ${ }^{3}$ Department of Medical Education, Catholic Kwandong University College of Medicine
}

\begin{abstract}
Objectives: The purpose of this study was to examine the curriculum of the medical humanities and social medicine at 11 Colleges of Korean Medicine (CKM) based on the Korean Medicine Education Accreditation Standards 2021 (KAS2021) and suggest ways to improve the quality of Korean Medical education in the future.

Methods: The curricula for each grade were collected from the websites of 11 CKM. Based on KAS2021, medical humanities and social medicine courses were extracted and compiled. Courses offered, frequency of course offerings, time of offerings, credits, and course hours were investigated.

Results: Courses in languages and literature were most frequently offered in CKM. Most medical humanities and social medicine courses were offered in the pre-medical program and the fourth year of the medical program and were conducted as individual courses. Developing a curriculum that integrates conceptual definitions of the medical humanities and social medicine with basic and clinical studies is necessary.

Conclusion: Eleven CKM should reorganize and operate their medical humanities and social medicine curricula based on each college's circumstances. This will allow each college to improve the quality of its educational offerings, creating a foundation for fostering excellent korean medicine doctors with professional medical skills and communication skills.
\end{abstract}

$\overline{K e y}$ Words
$\begin{gathered}\text { medicine } \\ \text { mes2021, Korean medical college, Korean medical education, Medical humanities, Social }\end{gathered}$

\section{Introduction}

In 2021, the Institute of Korean Medicine Education and Evaluation (IKMEE) proposed Korean Medicine Education Accreditation Standards $\left(\right.$ KAS2021) ${ }^{1)}$. These standards meet the basic medical education (BME) standards of the World Federation for Medical Education (WFME) and are designed to improve the quality of Korean Medical education and train high-quality Korean medicine doctors (KMD). KAS2021 focuses on performance -based, competency-oriented assessments of Korean medical education and emphasizes the continuous improvement of education programs. The education programs covered by KAS2021 include basic science medicine, basic Korean Medicine, clinical

\footnotetext{
- Received : 12 April 2021

- Revised : 11 May 2021

- Accepted : 18 May 2021

- Correspondence to : Su Jin Chae

Department of Medical Education

Simgokro 100Gil 25, Seo Gu, International St. Mary's Hospital Catholic Kwandong University, Incheon, Republic of Korea Tel : +82-32-290-3882, Fax : +82-32-290-3440, E-mail : edujin@cku.ac.kr
} 
science medicine, clinical Korean Medicine, and medical humanities and social medicine. The present study focused on 'medical humanities and social medicine' in Colleges of Korean Medicine (CKM).

Although there is no official consensus on the terms 'medical humanities and social medicine', it is considered to be an academic field that explores human health and disease from a biological, psychological, and sociocultural perspective based on the exploration of human nature and an understanding and relationships with others ${ }^{2}$. This field approaches medicine from a humanistic perspective using philosophy, literature, history, and ethics to explain health and medical problems from a social perspective. Forensic science, hospital administration, and public hygiene are used to find solutions.

Interest in the medical humanities and social medicine is a recent phenomenon in Korean medical education. However, CKM have expanded their offerings in this field based on global trends, and they have been included in the medical accreditation standards. But CKM do not have a clear concept of what medical humanities and social medicine entails, and have therefore not agreed about what to teach ${ }^{3,4,5)}$. KAS2021 ${ }^{1)}$ defined several subfields as part of the medical humanities and social medicine, including: medical ethics, medical law, medical statistics, medical informatics, behavioral science, preventive medicine, epidemiology, public health, hygiene, community social medicine, international health, medical care, medical education, social medicine, sociology of medicine, anthropology of medicine, forensic medicine, medical psychology, history of medicine, philosophy, art, language and literature, business administration, complementary and alternative medicine.

The KAS2021 require that at least one course or lecture in the medical humanities and social medicine be offered for each grade; each course must also include matters concerning medical professionalism and communication. The purpose of this study was to investigate the curriculum of medical humanities and social medicine at 11 CKM based on KAS2021 and to suggest how these schools should conduct medical humanities and social medicine education in the future.

\section{Methods}

\section{Study design}

This study investigated the pre-med and medical program curricula at $11 \mathrm{CKM}$ for the second semester of 2020 and the first semester of 2021.

\section{Data collection}

Using the KAS2021, courses at each of the 11 CKM were classified into the following categories of the basic science medicine, basic Korean Medicine, clinical science medicine, clinical Korean Medicine, and medical humanities and social medicine ${ }^{1)}$. Course information was taken from each school's website, department regulations, and from the curriculum mentioned in the Yearbook of Traditional Korean Medicine 2018 ${ }^{6}$.

\section{Data analysis}

Courses offered in the first and second years of the pre-med program and the first to fourth years of the medical program were examined, and those classified as medical humanities and social 
medicine were extracted. Information about the school name, course title, period of completion, number of credits, and number of course hours were analyzed.

Preventive medicine was classified as basic Korean Medicine because it is included by KAS2021 in basic Korean Medicine, basic science medicine, medical humanities and social medicine, and but it was excluded from the medical humanities and social medicine analysis.

\section{Results}

Table 1 shows the medical humanities and social

Table 1. Types of medical humanities and social medicine courses and the number of colleges that offer the courses

\begin{tabular}{|c|c|c|c|c|}
\hline \multicolumn{2}{|l|}{ Subfields } & Subjects & $\begin{array}{l}\text { No of } \\
\text { colleges }\end{array}$ & Classification \\
\hline \multicolumn{2}{|l|}{ Medical Ethics } & $\begin{array}{l}\text { Medical Ethical Studies, Medicine and Ethics, Medical Ethics, } \\
\text { Medical Science Ethics, Korean Medicine Ethics }\end{array}$ & 10 & Required \\
\hline \multirow{2}{*}{\multicolumn{2}{|c|}{ Philosophy }} & \multirow{2}{*}{$\begin{array}{l}\text { Eastern Philosophy, History of Eastern Philosophy, Medical } \\
\text { Philosophy, Korean Medicine Philosophy }\end{array}$} & \multirow{2}{*}{10} & Required \\
\hline & & & & Elective \\
\hline \multirow{7}{*}{$\begin{array}{l}\text { Language and } \\
\text { Literature }\end{array}$} & English & Medical English, English Conversation & 4 & Required \\
\hline & \multirow{3}{*}{ Chinese } & \multirow{3}{*}{$\begin{array}{l}\text { Chinese Reading, Chinese Conversation, Basic Chinese, Medical } \\
\text { Chinese, Readings in Chinese Medical Literature, Intermediate } \\
\text { Chinese, Chinese for Korean Medicine }\end{array}$} & \multirow{3}{*}{7} & Required \\
\hline & & & & Elective \\
\hline & & & & Other \\
\hline & \multirow{3}{*}{$\begin{array}{l}\text { Chinese } \\
\text { Literature }\end{array}$} & \multirow{3}{*}{$\begin{array}{l}\text { Medical Chinese Literature, Chinese Literature for Korean } \\
\text { Medicine, Chinese Literature, General Chinese Literature, } \\
\text { Ancient Medical Texts }\end{array}$} & \multirow{3}{*}{11} & Required \\
\hline & & & & Elective \\
\hline & & & & Other \\
\hline \multirow{2}{*}{\multicolumn{2}{|c|}{ Medical Statitics }} & \multirow{2}{*}{$\begin{array}{l}\text { Medical Statistical Studies, Theories in Medical Statistics, } \\
\text { Medical Statistics, Practice in Medical Statistics }\end{array}$} & \multirow{2}{*}{9} & Required \\
\hline & & & & Elective \\
\hline \multirow{2}{*}{\multicolumn{2}{|c|}{ Health Informatics }} & \multirow{2}{*}{ Korean Medicine Informatics, Medical Informatics } & \multirow{2}{*}{4} & Required \\
\hline & & & & Elective \\
\hline \multicolumn{2}{|c|}{$\begin{array}{l}\text { Complementary and } \\
\text { Alternative Medicine }\end{array}$} & Complementary Integrated Medicine & 1 & Elective \\
\hline \multicolumn{2}{|c|}{ Sociology of Medicine } & Medicine and Society & 1 & Elective \\
\hline \multicolumn{2}{|c|}{ Medical Leadership } & Medical Leadership & 1 & Elective \\
\hline \multicolumn{2}{|l|}{ Career } & $\begin{array}{l}\text { Self-understanding and Career Design, Specialized Practice, } \\
\text { Practice in Career Experience }\end{array}$ & 3 & Required \\
\hline \multicolumn{2}{|l|}{ Science History } & Perception and History of Science & 1 & Elective \\
\hline \multirow{2}{*}{\multicolumn{2}{|c|}{ Business Administration }} & \multirow{2}{*}{ Hospital Management, Hospital Management and Practice } & \multirow{2}{*}{4} & Required \\
\hline & & & & Elective \\
\hline \multirow{2}{*}{\multicolumn{2}{|c|}{ Forensic Medicine }} & \multirow{2}{*}{ Forensic Medicine } & \multirow{2}{*}{6} & Required \\
\hline & & & & Elective \\
\hline Public Health L & & Health Law, Healthcare Law, Medical Law & 11 & Required \\
\hline & unication & & & Required \\
\hline Medical Comm & unication & Medical Interviews, Medical Communicatıon & 2 & Elective \\
\hline & & & & Required \\
\hline Medical Psycho & $\operatorname{logy}$ & Clinical Psychology, Psychology. & 3 & Elective \\
\hline Community $\mathrm{Me}$ & dicine & Community Clinical Practice & 1 & Required \\
\hline Medical Manag & ement & $\begin{array}{l}\text { Hospital Administration, Medical Management, Medical } \\
\text { Insurance and Hospital Administration }\end{array}$ & 3 & Required \\
\hline
\end{tabular}


medicine courses offered at the $11 \mathrm{CKM}$ examined, as presented in KAS2021. The analysis showed that medical humanities and social medicine courses were offered, either as required or as elective courses, in all $11 \mathrm{CKM}$.

Table 2 shows the medical humanities and social medicine courses offered at the $11 \mathrm{CKM}$ and their categories, years, credits, and course hours. Students took medical humanities and social medicine courses most often in the second year of the pre-med program, followed by the first year of the pre-med program and fourth year of the medical program. The range of average credits and course hours for each course was 1.14-3.50 credits and 1.0-7.7 hours, respectively. The average number of medical humanities and social medicine courses was 5.3 for the pre-med program and 3 for the medical program. All 11 colleges offered public health law as a subject in the medical program.

\section{Discussion}

The World Health Organization (WHO) strives to establish accreditation mechanisms for health and medical training institutions in all countries. Periodically, the WFME revises international standards for basic medical education to reflect the changing educational environment ${ }^{7}$. Korean Medical education must also transform over time. KAS2021 proposed by the IKMEE was developed to reflect the current trends in medical education, including medical humanities and social medicine programs, which were the focus of this study. Based on the KAS2021 ${ }^{1)}$, CKM must offer at least one medical humanities and social medicine course for each grade, including content about medical professionalism and communication. In the present study, the authors examined the curriculum of the medical humanities and social medicine at CKM, and recommend how these schools should conduct medical humanities and social medicine education such that they meet KAS2021.

The analysis results and consequent suggestions are as follows.

First, in terms of the frequency of offered subjects, Chinese literature and medical law were most frequently offered, which were offered in all 11 CKM, followed by medical ethics and philosophy, which were offered in 10 colleges. Chinese literature was offered as an 8 credit course, which was the largest number of credits offered. Although Language and Literature are classified under medical humanities and social medicine by KAS2021 standards, its place within this classification must be discussed. Medical humanities and social medicine can be defined in various ways, from 'an interdisciplinary concept that encompasses humanties or social science subject matters relevant to facilitating the understanding and practice of medicine' to 'an approach to promote good medical practice ${ }^{8-10)}$. Considering that medical humanities and social medicine aims to promote a comprehensive understanding and reflection on humanity, patient and disease, as well as the role of a doctor in Korean Medicine in society, there is a need for clear classification of what course can be included in this field.

Second, in terms of the offered timing, KAS2021 requires that 'at least one medical humanities and social medicine course be offered for each grade', 
Table 2. Educational Status of Medical Humanities and Social Science Courses in 11 Colleges of Korean Medicine (Number: credit, Parentheses: hours)

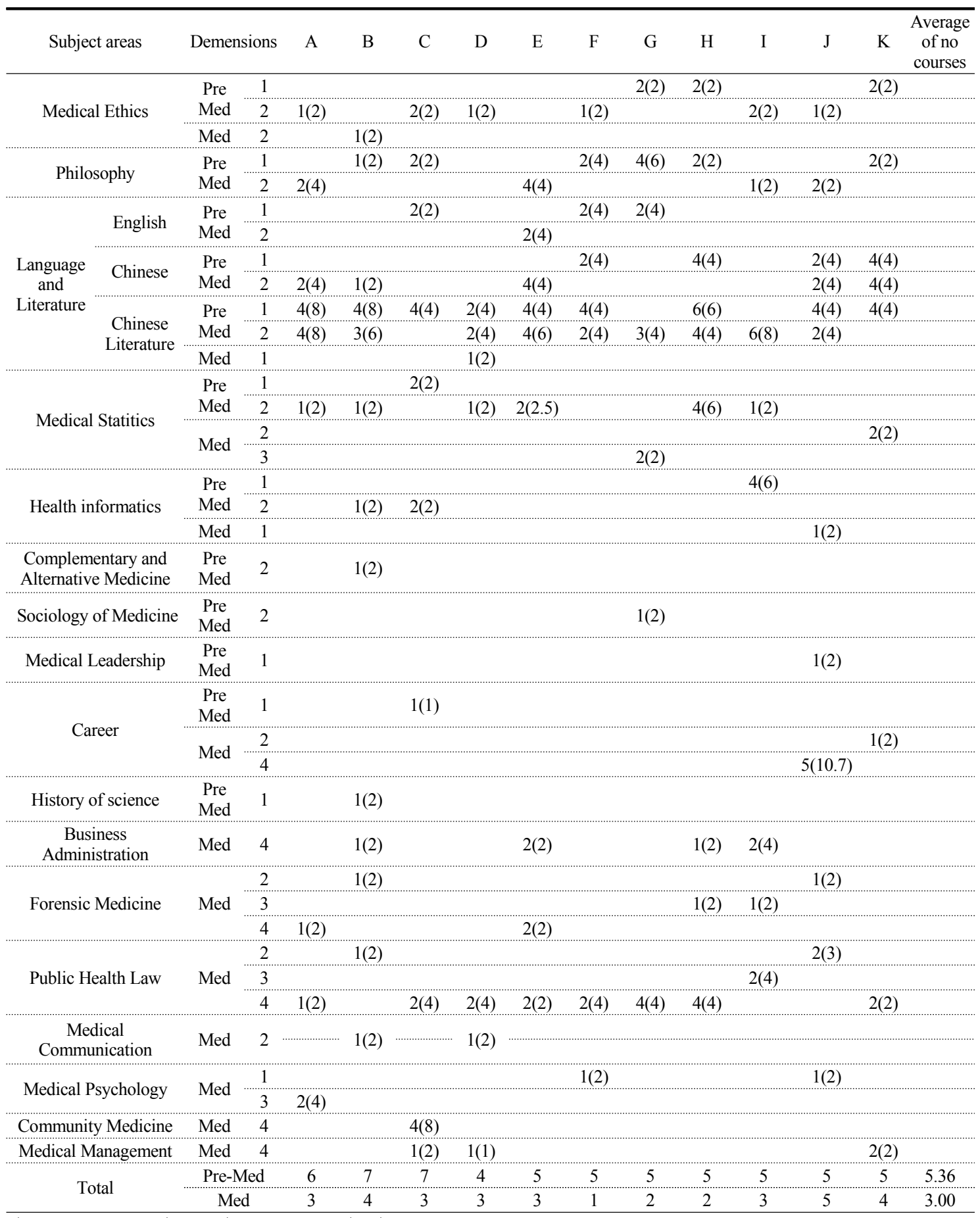

1) Pre Medical Course(Pre-med), Medical Course(Med) 
but no CKM that satisfied this criterion. CKM were teaching five to six medical humanities and social medicine courses on average in the pre-med program. All the 11 colleges were teaching 'public health law' in the medical program. The average number of these courses in the medical program was 3, all of which were offered in the fourth year. This does not adhere to the KAS2021. The fact that CKM mostly offered public health law in the fourth year can be seen as the impact of the national medical licensing examination.

Moreover, although KAS2021 'requires matters related to the inclusion of classes on medical profession and communication,' only two colleges offered communication-related courses. In medical schools, courses such as patient-doctor relationships, doctor-social relationships, or communication skills between patients, caregivers, and colleagues are taught as a requirements prior to beginning clinical practice $^{11)}$. Considering that the purpose of medical humanities and social medicine education is the comprehensive understanding and reflection of disease, patients, and society, the field should be taught throughout CKM curriculum instead of limiting the courses to teaching periods that do not interfere with basic and clinical medicine courses or the national medical licensing examination.

Third, in terms of integrated education, there was almost no integration in education between the medical humanities and social medicine subjects that were taught in conjunction with basic science medicine and clinical studies, or subjects offered in a particular grade or time period. Most courses were offered as individual subjects. KAS2021 ${ }^{1)}$ recommends that basic science medicine, basic Korean Medicine, medical humanities and social medicine, and the clinical medicine curriculum be integrated horizontally or vertically. To link theory and practice and form organic relationships with other subjects, interdisciplinary course offerings should be increased, and the curriculum should be organized based on experience-based learning instead of treating medical humanities and social medicine as a separate academic discipline. In other words, it is necessary to establish a system of integrated education that combines clinical medicine, such as medical statistics, medical informatics, business management and medical management, with subjects like philosophy, the history of science, and medical history. Medical counselling could also be offered in conjunction with clinical practice courses such as clinical medicine and clinical performance examination ${ }^{12)}$.

Finally, comparing the medical humanities and social medicine classification in KAS2021 with the courses included in the curriculums of $11 \mathrm{CKM}$ showed that there were subjects included in the KAS2021 that were offered only in a few colleges or not offered at all. For example, there was no CKM that offered courses related to arts or medical education. Furthermore, although complementary and alternative medicine was offered in one college, it was difficult to identify the purpose and meaning of offering it in the CKM in this study. It is necessary to review and agree on why CKM should offer such subjects as 'arts', 'medical education', and 'complementary and alternative medicine'. The classification issue regarding whether preventive medical and medical history should be included as basic Korean medicine or in the medical humanities and social medicine needs to be discussed. KAS2021 classifies medical 
history as basic Korean medicine, but the validity of this classification is controversial. There were four colleges that offered courses related to health informatics. It is necessary to discover new content in line with current trends and to evaluate and improve existing education to cultivate graduates with the best medical competency in the new normal era. Although it is not currently covered by the classification system in KAS2021, it is necessary to review in the future the contents of professional identity formation courses such as 'becoming a doctor', 'death', 'hospice', 'interprofessional education', and 'patient safety', etc.

\section{Conclusions}

The year 2021 marks the first year that KAS2021 is applied to accreditation. If CKM across the country face this challenge by reorganizing and operating their medical humanities and social medicine curricula based on each college's circumstances, this will improve the quality of Korean Medical education and can foster the training of excellent Korean Medicine Doctors with professional medical and communication skills.

The year 2021 marks the first year that KAS2021 is applied to accreditation. If CKM across the country face this challenge by reorganizing and operating their medical humanities and social medicine curricula based on each college's circumstances, it will improve the quality of Korean Medical education and can foster the training of excellent Korean Medicine Doctors with professional medical and communication skills.

Since data were gathered through curricula mentioned in the 11 CKM's websites in 2020, the actual courses offered may have differed. Additionally, since colleges may be reorganizing their curricula in preparation for KAS2021, their curricula context may change. Most, but not all, colleges presented their revised curriculum online, so there may be an overlap in the completion period for certain subjects due to changes.

Despite these limitations, identifying the current status of the medical humanities and social medicine curriculum as it reflects KAS2021 is necessary to develop medical humanities and social medicine courses, which are an important part of Korean medical education. Furthermore, the KAS2021 will be applied starting in 2021 and can be used as a foundational material to discuss reforming the medical humanities and social medicine curriculum at CKM. This will allow for the evaluation of the revised performance-based, competency-based Korean medical education at a level above the WFME's international standard of basic medical education through the accreditation of Korean Medicine in the first period of 2012-2017 and the accreditation of Korean Medicine in the second period of 2017-2020.

\section{References}

1. Institute of Korean Medicine Education \& Evaluation. Teaching Medical Humanities in Korean Medical Schools: Tasks and Prospect. Korean J Med Educ 2019;19:1-119. https://doi.org/10.3946/kjme.2007.19.1.5.

2. Meng KH. Teaching medical humanities in Korean medical schools: Tasks \& prospect. Korean J Med Educ 2007;19:5-11.

3. Cheon ME, Lim BM, Shin SW. Education of 
medical humanities and social medicine in schools of Korean medicine in Korea. Korean J Orient. Prev Med 2012;16:31-42. https://doi.org/10. 13048/jkm.15015.

4. Yu J, Cheon M, Lim B, Kwon Y, Kim BJ. Awareness and attitudes of professors regarding research ethics education in the colleges and the school of Korean Medicine. J Korean Med 2015;36:1-13.

5. Lee HJ, Hong JW, Hong SP, Lim YK, Kim Dk JJG, Lee SY, Kwon YK. Attitudinal study of Korean oriental medical doctors toward the educational necessity of human social medical study in the curriculum of Korean oriental medicine. Korean J Orient Physiol Pathol 2010;24:1134-1141.

6. Korea Institute of Orental Medicine. Yearbook of Traditional Korean Medicine. 2018:70-117.

7. Basic WFME. Medical education. WFME Glob Stand Qual Improv 2021 [cited 2021 Month DD].

8. An JH, Kwon I, Lee SN, Han JJ, Jeong JE. Study on the medical humanities and social sciences curriculum in Korean medical school: Current teaching status and learning subjects. Korean J Med Educ 2008;20:133-144. https://doi.org/10.3946/kjme.2008.20.2.133.

9. Kim GW, Koh Y, Lim CM, Huh JW, Jung SH, Kim JB, Hong SB. The effect of medical interview course in Korean medical school. J Korean Med 2012;33:121-129. https://doi.org/ $10.3904 / \mathrm{kjim} .2015 .027$.

10. Wootaek J. Suggestions for the improvement of medical humanities education. Korean Educ Rev 2010;12:23-31.

11. Hojong Y. Two aims of medical humanities education: Good doctors and happy doctors. Korean Educ Rev 2015;17:51-56. https://doi.org/ 10.17496/kmer.2015.17.2.51.

12. Kwang-ho M. Teaching medical humanities in Korean medical schools: Tasks and prospect. Korean J Med Educ 2007;19:15-11. https://doi.org/ 10.3946/kjme.2007.19.1.5.

\section{ORCID}

So-Youn Park https://orcid.org/0000-0003-0553-5381

Gwanwook Bang https://orcid.org/0000-0002-9998-0226

Seong-Hun Choi https://orcid.org/0000-0002-5942-1550

Su Jin Chae http://orcid.org/0000-0003-3060-8933 